\title{
Imitating the Child with Autism: A Strategy for Early Intervention?

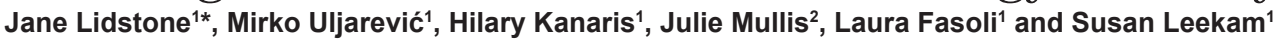

${ }^{1}$ School of Psychology, Cardiff University, UK

${ }^{2}$ Speech and Language Therapy, Cardiff and Vale University Health Board, UK

\begin{abstract}
Research indicates that imitation is a promising strategy for early intervention with children who have autism. Using a single case design we studied the effectiveness of an established imitation-based intervention, Intensive Interaction, for two 3-year-olds with autism. Outcome measures were the propensity to give social attention during imitation sessions and during free play with a researcher. Social attention did not increase over the course of the intervention phase for either child or during free play with the researcher. Thus, there was no evidence of intervention effectiveness.
\end{abstract}

\section{Introduction}

Autism spectrum disorder (ASD) is defined by socialcommunication impairment and restricted and repetitive behavior. One of the earliest signs of ASD is reduced social attention [1,2]. Reduced social attention is considered to be a behavioural manifestation of reduced social interest $[3,4]$ which has cascading effects on development by restricting a child's social experience $[5,6]$.

Comprehensive interventions for young children with ASD have produced gains in IQ, language ability, and adaptive functioning $[7,8]$, and targeted interventions have been successful in increasing the frequency of specific social behaviours [9-11]. However, little is known about what increases social interest in ASD-a notable gap considering the potential for reduced social interest to disrupt subsequent development.

One technique that may increase the social interest of children with ASD is imitation. Experiments have indicated that children with ASD show more social behaviours while being imitated by an adult than when the adult is interacting in other ways [12], and that children with ASD show more social interest immediately after being imitated than immediately after other contingent responding [13-16]. Zeedyk [17] suggests that imitation functions as a particularly effective way of creating intimacy, by providing "the closest correspondence between self and other" p. 331. Consequently, imitating the child with ASD is considered a promising strategy for early intervention $[15,16,18,19]$. Imitation-based interventions may have advantages over more comprehensive interventions in that they are easy for therapists to learn [20] and may have rapid effects [21].

To our knowledge there has been only one quantitative test of the efficacy of an imitation-based intervention for children with ASD. This was a case study reporting the effect of Intensive Interaction on the peer interaction of a 6-year-old boy with autism, "Philippe" (a pseudonym) [22]. Intensive Interaction, widely used in the UK [23], is an intervention that focuses on dyadic interaction and involves playfully imitating the child's actions, vocalizations, and facial expressions [17,24]. Argyropoulou and Papoudi [22] measured aspects of Philippe's interaction with his non-autistic peer, "Anna", during baseline, intervention, and follow-up phases, with the whole study lasting 2 months. During the intervention phase these interactions took place immediately after Philippe's Intensive Interaction sessions. For each peer interaction, the authors measured the frequency of Philippe's and Anna's social initiations and responses. The findings indicated that Philippe's social initiations increased from baseline to the intervention phase; however Philippe's initiations returned to baseline levels during the follow-up phase. Anna (who had not received Intensive Interaction) increased in her propensity to initiate interactions with Philippe, showing an increase in the frequency of initiations from the baseline to the intervention phase, and this was partially maintained at follow-up; Philippe's responses to Anna's initiations showed the same pattern. This study therefore provided some support for the efficacy of an imitation-based intervention in improving the social interactions of a child with ASD. However, social attention was not measured in this study.

The present study was, to our knowledge, the first to test the effect of an imitation-based intervention on the social attention of children with ASD. Hypothesis 1 was that, over the course of the 10- to 12week intervention, there would be a week-by-week increase in the children's social attention during imitation sessions. Hypothesis 2 was that this increase in the children's social attention with the therapist during imitation sessions would generalize to free play sessions with a researcher. Given the need for weekly measurement, single case design was used, with two participants.

\section{Method}

\section{Participants}

The participants were two 3-year-old boys with clinical diagnoses of ASD which were independently verified for this research using the Autism Diagnostic Observation Schedule [25]. The expressive language items of the Diagnostic Interview for Social and Communication Disorders [26], administered at the start of the study, indicated that Child A was preverbal and Child B used phrase speech. Neither child was diagnosed with any other medical or neurodevelopmental condition.

\section{Overview}

Each child visited the laboratory approximately weekly over a

*Corresponding author: Dr. J. Lidstone, Department of Psychology, Durham University, Science Laboratories, South Road, Durham, DH1 3LE, United Kingdom, Tel: +44 (0) 191334 3243; Fax: +44 (0) 191334 3241; E-mail: jane.lidstone@durham.ac.uk

Received December 23, 2013; Accepted January 27, 2014; Published February 03, 2014

Citation: Lidstone J, Uljarević M, Kanaris H, Mullis J, Fasoli L, et al. (2014) Imitating the Child with Autism: A Strategy for Early Intervention? Autism 4: 124 doi:10.4172/2165-7890.1000124

Copyright: @ 2014 Lidstone $\mathrm{J}$, et al. This is an open-access article distributed under the terms of the Creative Commons Attribution License, which permits unrestricted use, distribution, and reproduction in any medium, provided the original author and source are credited. 
5-month period. The first set of sessions constituted a baseline phase (Child A: 9 sessions; Child B: 8 sessions), the second set, the intervention phase (Child A: 10 sessions; Child B: 12 sessions), and, the last set, a post-intervention phase (Child A: 1 session; Child B: 2 sessions). Each visit included a play session with a researcher for the measurement of social attention. During the intervention phase this was followed by an intervention session. All sessions were recorded with cameras operated from a control room. The study was approved by the Cardiff University School of Psychology Research Ethics Committee.

\section{Procedure}

\section{Intervention}

A speech and language therapist delivered weekly one-hour sessions of Intensive Interaction. The intervention involved playfully imitating the child's actions, vocalizations, and facial expressions. ${ }^{1}$ Intervention sessions mostly involved no toys. The therapist was trained in Intensive Interaction and had used it in clinical practice for more than 10 years.

The first author assessed a random $25 \%$ of the sessions for fidelity of implementation. The video-recordings were divided into 10 -second segments, and each segment was coded for the presence/absence of imitation. To assess the inter-rater reliability (IRR) of this coding, $25 \%$ of these recordings were also coded independently by a second researcher; this researcher coded several aspects of the intervention sessions and was not told that imitation was intended to be the key ingredient. IRR for the presence/absence of imitation in each segment was $\kappa=.80$ (representing agreement on $96 \%$ of segments). The coding revealed that, in each session, imitation occurred during more than $96 \%$ of the segments. Imitation paused only when the child was not doing anything or the child was doing something undesirable (e.g., hitting). Fidelity of implementation was therefore high.

\section{Play sessions with a researcher}

At the start of each visit, the child played with one of two researchers. The choice of researcher each week was randomized. Each was unaware of the name and nature of the intervention and its intensity, duration, and start date. Each session started with a tickle game ( $3 \mathrm{~min})$; then the child was seated at a table holding five simple toys and an interactive play session took place $(3 \mathrm{~min})$, followed by a free play session $(3.5$ $\mathrm{min})$. The tickle game and interactive play session established the researcher as a fun playmate, and the free play session was a more tightly-controlled procedure designed to allow measurement of the children's propensity to initiate social attention. The researcher sat beside the child, paying him attention but not initiating interaction, so that the child was free to initiate or not initiate social attention [27].

\section{Coding of Social Attention}

Each session's video-recording was later coded by a researcher

${ }^{1}$ Zeedyk [17] notes that some Intensive Interaction practitioners resist reducing this intervention to the somewhat mechanistic definition of imitation apparent in much of the imitation literature. According to Zeedyk, rather than merely copying specific actions, the Intensive Interaction practitioner engages in a kind of imitation which includes but is broader than this. This expanded definition of imitation includes matching the client's behaviors, but also their emotional expressions and bodily postures, and imitation incorporates correspondence with the client in the "rhythm, pitch, timing, and intensity" of actions as well as the actions themselves. Thus, the aim of an Intensive Interaction practitioner is "to match the client's own behavior as a way of supportively drawing him .... into sympathetic engagement with others" p. 335 [17]. Caldwell [24] characterizes the imitation that occurs during Intensive Interaction not as merely mimicry but, rather, as communicating in the client's language. Although these are different ways of describing imitation, each of these accounts is consistent with the idea that Intensive Interaction is an imitation-based intervention. blind to the order in which sessions occurred. $25 \%$ of the videos were coded independently by other personnel for the assessment of IRR (intra-class correlation coefficients below)

The first 10 minutes of each intervention session were coded for social attention. An episode of social attention was coded when the child looked at the eye-region of the therapist's face. As toys were rarely used, initiations of joint attention were very rare and are not presented. IRR for the number of episodes per minute was .93. The duration of each episode was also recorded, as the intervention sessions included some long episodes of up to 23 seconds. IRR for the duration of episodes was .93. The durations were summed to give the total duration of social attention in seconds per minute.

Free play sessions with the researchers were also coded for social attention. An episode of social attention was coded when the child
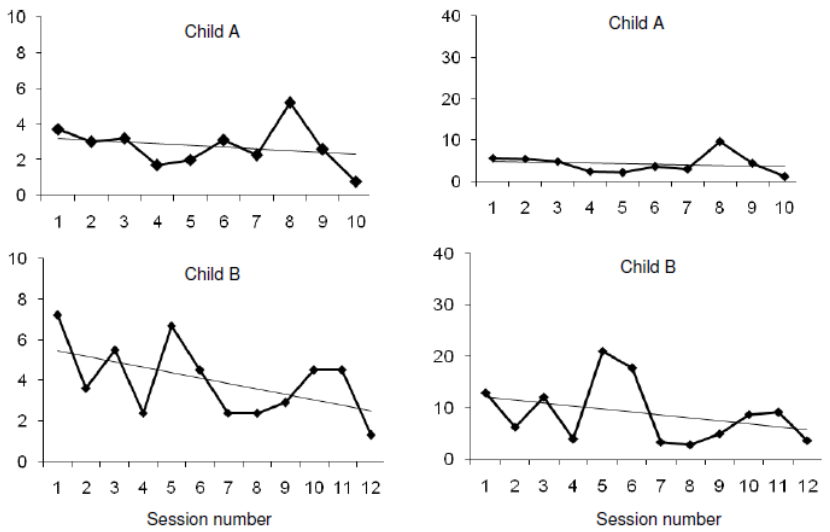

Figure 1: Social Attention during Intervention Sessions with the Therapist. a Frequency of social attention (episodes per min). b. Duration of social attention (seconds per min)

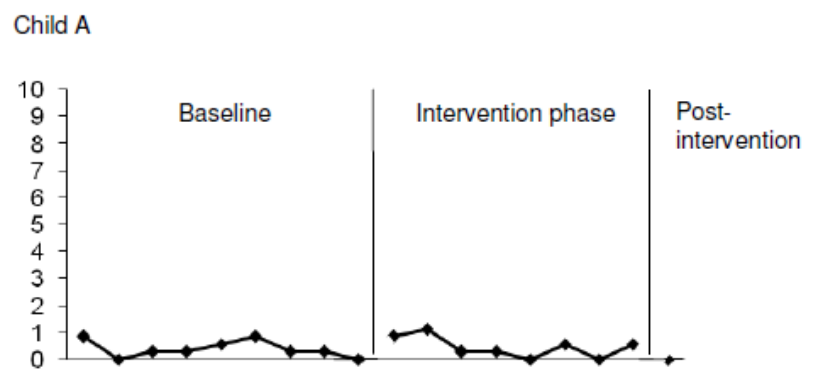

Child B

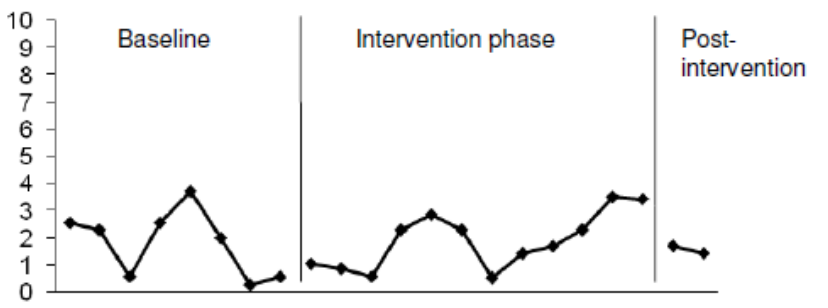

Figure 2: Number of Episodes of Social Attention per Minute during Free Play with the Researcher. 
looked at the eye-region of the researcher's face. One child occasionally initiated joint attention by pointing to, showing, or giving a toy to the researcher. These initiations were included to avoid penalizing the child for initiating more advanced social attention. IRR for the number of episodes of per minute was 96 .

\section{Results and Discussion}

Figure 1a shows the frequency of social attention episodes during intervention sessions, and Figure $1 \mathrm{~b}$ shows the duration of social attention per minute during intervention sessions. None of the four graphs shows the amount of social attention increasing over the course of the intervention period; thus, Hypothesis 1 was not supported. Figure 2 shows the frequency of social attention episodes during free play with the researcher. Again, there was no upward trend for either child-at no point during the intervention or follow-up phase did the frequency of social attention outstrip that found during the baseline phase. Therefore there was no support for Hypothesis 2. In sum, there appeared to be no beneficial effect of the intervention on the children's social attention. This was despite the high level of fidelity of implementation, the relatively high "dose" of intervention (10-12 hours per child), the high level of experience of the therapist, and the fact that the intervention sessions were characterized by a high level of engagement, as evidenced by the fact that the children looked at the therapist's face several times per minute while being imitated (Figure 1).

At first sight, this is perhaps surprising given the body of research cited in the Introduction suggesting that imitation-based intervention is likely to be beneficial for children with ASD. However, there are two key differences between the previous studies and the present study. Firstly, previous work has measured social attention during imitation sessions, finding it to be high [12], but did not report on the cumulative effect of multiple imitation sessions. The present study in combination with previous work indicates that, although imitation may produce a high level of engagement, this does not build with repeated sessions, as we would expect it to if imitation is having an effect on the child. Secondly, previous studies have measured only the immediate effects of imitation, observing social interaction improving in the few minutes immediately following imitation [13-16,22], but previous papers have not reported whether or not this is maintained over the next few hours, days, or weeks. The present study measured social attention with the researcher immediately before each imitation session, on the assumption that, if imitation is increasing the child's social interest, then the effects of all the previous imitation sessions should be apparent beyond the few minutes immediately following the last session. However, there was no evidence that the effects of the last session could be detected a week after the last session. Therefore the present study in combination with previous work suggests that imitation may increase a child's responsiveness immediately after being imitated but the effect is short-lived.

Of course, a degree of caution must be exercised when comparing results across studies. In addition, it is important to consider aspects of the methodology which might have had an effect on the results of the present study. There are two we would like to raise here. Firstly, we focused on social attention as an outcome measure and it is possible that the intervention was beneficial for the participants' social development in other ways, for example, by increasing their enjoyment in social interactions. Both families indicated that the child had enjoyed the sessions and expressed great satisfaction with the work of the therapist, requesting follow-up sessions with the therapist after the end of the study. Although the parents may have thought that their children were making progress as a result of the therapy, other outcome measures would be needed in order to establish whether this could be attributed to the therapy. Social attention is a well established behavioral index of social motivation, considered to be an important outcome measure for intervention studies [4]. In future studies, however, researchers may wish to include a greater variety of outcome measures.

The second methodology-related point is that it is possible that the children in the present study were unusual in not being responsive to the intervention-this is a possibility when single case design is used. This research therefore awaits replication in other laboratories. In future studies researchers may wish to test the hypothesis suggested above, that imitation increases the responsiveness of children with ASD in the few minutes following the imitation session, but this is not maintained over the next few hours or days. Future work could also consider other types of benefits that do not depend on the intervention having medium- to long-term effects. For example, imitation may have value in terms of increasing the closeness of children's relationships with their parents and therapists; it might also increase children's responsiveness to other intervention strategies that can be demonstrated to improve social attention. In the meantime, the results of the present study were quite clear and consistent across the two participants-there was no evidence to suggest a benefit of imitation-based interventions for the social attention of children with ASD.

\section{Acknowledgement}

The study was supported by a project grant from the Baily Thomas Charitable Fund (awarded to SL). We thank the two families for their enthusiastic participation and the following for their advice and assistance: Katy Bowen, Liliya Dankova, Kate Ellis-Davies, Mark Freeston, Dale Hay, Ann Le Couteur, Helen McConachie, Anne Marie McKigney, Ruth Paradice, Margot Prior, Deborah Riby, Jacqui Rodgers, and Anisha Tanna

\section{References}

1. Clifford S, Young R, Williamson P (2007) Assessing the early characteristics of autistic disorder using video analysis. J Autism Dev Disord 37: 301-313.

2. Zwaigenbaum L, Bryson S, Rogers T, Roberts W, Brian J, et al. (2005) Behavioral manifestations of autism in the first year of life. Int $\mathrm{J}$ Dev Neurosci 23: 143-152.

3. Chevallier C, Kohls G, Troiani V, Brodkin ES, Schultz RT (2012) The social motivation theory of autism. Trends Cogn Sci 16: 231-239.

4. Dawson G, Bernier R, Ring RH (2012) Social attention: a possible early indicator of efficacy in autism clinical trials. J Neurodev Disord 4: 11.

5. Dawson G, Toth K, Abbott R, Osterling J, Munson J, et al. (2004) Early socia attention impairments in autism: social orienting, joint attention, and attention to distress. Dev Psychol 40: 271-283.

6. Mundy P, Newell L (2007) Attention, Joint Attention, and Social Cognition. Curr Dir Psychol Sci 16: 269-274.

7. Dawson G, Rogers S, Munson J, Smith M, Winter J, et al. (2010) Randomized, controlled trial of an intervention for toddlers with autism: the Early Start Denver Model. Pediatrics 125: e17-23.

8. Howlin P, Magiati I, Charman T (2009) Systematic review of early intensive behavioral interventions for children with autism. Am J Intellect Dev Disabil 114: 23-41.

9. Kaale A, Smith L, Sponheim E (2012) A randomized controlled trial of preschool-based joint attention intervention for children with autism. J Child Psychol Psychiatry 53: 97-105.

10. Kasari C, Gulsrud AC, Wong C, Kwon S, Locke J (2010) Randomized controlled caregiver mediated joint engagement intervention for toddlers with autism. $J$ Autism Dev Disord 40: 1045-1056.

11. Matson JL, Minshawi NF (2006) Early intervention for autism spectrum disorders: A critical analysis. Assessment and Treatment of Child Psychopathology and Developmental Disabilities 1: 1-150. 
Citation: Lidstone J, Uljarević M, Kanaris H, Mullis J, Fasoli L, et al. (2014) Imitating the Child with Autism: A Strategy for Early Intervention? Autism 4: 124. doi:10.4172/2165-7890.1000124

Page 4 of 4

12. Dawson G, Adams A (1984) Imitation and social responsiveness in autistic children. J Abnorm Child Psychol 12: 209-225.

13. Escalona A, Field T, Nadel J, Lundy B (2002) Brief report: imitation effects on children with autism. J Autism Dev Disord 32: 141-144.

14. Field T, Field T, Sanders C, Nadel J (2001) Children with autism display more social behaviors after repeated imitation sessions. Autism 5: 317-323.

15. Heimann M, Laberg KE, Nordoen B (2006) Imitative interaction increases social interest and elicited imitation in non-verbal children with autism. Infant and Child Development 15: 297-309.

16. Sanefuji W, Ohgami $H$ (2011) Imitative behaviors facilitate communicative gaze in children with autism. Infant Mental Health Journal 32: 134-142.

17. Zeedyk MS (2006) From inter-subjectivity to subjectivity: The transformative roles of emotional intimacy and imitation. Infant and Child Development 15: 321-344.

18. Katagiri M, Inada N, Kamio Y (2010) Mirroring effect in 2- and 3-year-olds with autism spectrum disorder. Research in Autism Spectrum Disorders 4: 474-478.

19. Nadel J (2006) Does imitation matter to children with autism? In SJ Rogers \& JHG Williams (Eds.) Imitation and the Social Mind: Autism and typical development. New York: The Guilford Press 118-137.

20. Zeedyk S, Caldwell P, Davies C (2009) How rapidly does Intensive Interaction promote social engagement for adults with profound learning disabilities and communicative impairments? European Journal of Special Needs Education 24: 119-137.

21. Zeedyk S, Davies C, Parry S, Caldwell P (2009) Fostering social engagement in Romanian children with communicative impairments: The experiences of newly trained practitioners of Intensive Interaction. British Journal of Learning Disabilities 37: 186-196.

22. Argyropoulou Z, Papoudi D (2012) The training of a child with autism in a Greek preschool inclusive class through Intensive Interaction: A case study. European Journal of Special Needs Education 27: 99-114.

23. Charman T, Pellicano E, Peacey LV, Peacey N, Forward K, et al. (2011) What is good practice in autism education? Report prepared for the Autism Education Trust.

24. Caldwell $P$ (2006) Speaking the other's language: Imitation as a gateway to relationship. Infant and Child Development 15: 275-282.

25. Lord C, Rutter M, DiLavore PC, Risi S (2001) Autism Diagnostic Observation Schedule. Western Psychological Services.

26. Wing L, Leekam SR, Libby SJ, Gould J, Larcombe M (2002) The Diagnostic Interview for Social and Communication Disorders: background, inter-rater reliability and clinical use. J Child Psychol Psychiatry 43: 307-325.

27. Leekam SR, Ramsden CA (2006) Dyadic orienting and joint attention in preschool children with autism. J Autism Dev Disord 36: 185-197.
Citation: Lidstone J, Uljarević M, Kanaris H, Mullis J, Fasoli L, et al. (2014) Imitating the Child with Autism: A Strategy for Early Intervention? Autism 4: 124. doi: $10.4172 / 2165-7890.1000124$
Submit your next manuscript and get advantages of OMICS Group submissions

Unique features:

- User friendly/feasible website-translation of your paper to 50 world's leading languages

Audio Version of published paper

Digital articles to share and explore

Special features:

300 Open Access Journal

25,000 editorial team

21 days rapid review process

Quality and quick editorial, review and publication processing

Indexing at PubMed (partial), Scopus, EBSCO, Index Copernicus and Google Scholar etc

Sharing Option: Social Networking Enabled

- Authors, Reviewers and Editors rewarded with online Scientific Credits

Better discount for your subsequent articles

Submit your manuscript at: http://www.omicsonline.org/submission/ 